\title{
'Your mind is part of your body': negotiating the maternal body in online stories of postnatal depression on Mumsnet
}

Article

Accepted Version

Creative Commons: Attribution-Noncommercial-No Derivative Works 4.0

Kinloch, K. and Jaworska, S. ORCID: https://orcid.org/00000001-7465-2245 (2021) 'Your mind is part of your body': negotiating the maternal body in online stories of postnatal depression on Mumsnet. Discourse, Context and Media, 39. 100456. ISSN 2211-6958 doi:

https://doi.org/10.1016/j.dcm.2020.100456 Available at https://centaur.reading.ac.uk/94906/

It is advisable to refer to the publisher's version if you intend to cite from the work. See Guidance on citing.

To link to this article DOI: http://dx.doi.org/10.1016/j.dcm.2020.100456

Publisher: Elsevier

All outputs in CentAUR are protected by Intellectual Property Rights law, including copyright law. Copyright and IPR is retained by the creators or other copyright holders. Terms and conditions for use of this material are defined in the End User Agreement. 


\section{www.reading.ac.uk/centaur}

\section{CentAUR}

Central Archive at the University of Reading

Reading's research outputs online 


\section{'Your mind is part of your body': Negotiating the maternal body in online stories of postnatal depression on Mumsnet}

\section{Abstract}

This paper looks at the intersection between motherhood and online illness narratives, examining the ways in which women conceptualise their maternal bodies in the context of postnatal depression. Specifically, we examine how discourses of motherhood in distress are positioned in relation to societal norms and expectations, and the othering of the 'imbalanced' maternal body. To do so, we apply corpus assisted discourse analysis to posts made in the Mumsnet Talk forum, which specifically discuss postnatal depression. Our findings highlight the discursive strategies employed to represent embodied experiences of a stigmatised condition in an online forum. We focus particularly on the use of embodied explanatory models for mental ill health in mothers to mitigate the stigma attached to the condition. Our study also shows how the embodied lived experience continually interacts with states of mind when making sense of PND and in doing so, transgresses the boundaries set by the body/mind dualism, which prevails in modern medicine.

\section{Introduction}

The experience of giving birth and caring for a newborn is both a huge physical and psychological challenge. It involves rapid changes to the body during pregnancy and after giving birth, and creates new demands on the body that can lead to feelings of frustration, anxiety and disappointment. Yet, these 'messy' physical and psychological realities are not easily disclosed (Choi, et al., 2007; Kantrowitz-Gordon, 2013; Woody et al., 2017). One of the explanations for hiding these 'divergent' experiences is that they do not quite fit what is socially regarded as 'good' or 'correct' motherhood experience (Hays, 1996; Choi et al., 2007). The socially expected image of 'good' mothers is, at least in the Western culture, based on mothers with well-functioning and ideally pre-pregnancy bodies, who are jolly, selfless, and prioritise the child over everything else - an image largely mythologised and perpetuated through popular culture (Hall, 1996; Woodward, 2003). Having feelings or experiences other than that can constitute a maternal 'sin' (Kantrowitz-Gordon, 2013) and it is not something to be easily admitted. Following Butler (1990), Choi et al. (2007: 169) point out this is because there are 
"societal retributions" for not performing up to the social expectations and these can include stigmatisation, shaming and exclusion. The aim of this paper is to shed light on some of the hidden discourses of motherhood in the context of a 'divergent' experience, here specifically that of postnatal depression (PND), also known as postpartum depression. We do so by analysing a large set of posts discussing PND that were posted on the parenting website Mumsnet.

There has been a proliferation of Internet help- and advice-seeking (Locher, 2006), particularly in the realm of health and parenthood (Pedersen, 2016). Parental helpseeking is not merely focused on information and advice on practical matters of childraising; it is also a bid for social and emotional support. The role of the digital in parenthood is complex: its democratising and empowering potential for parents has been contested (e.g. Jang and Dworkin, 2014), yet digital environments such as blogs or discussion fora have opened up spaces for parents to negotiate, re-negotiate or even subvert notions of parenthood/motherhood under new, different or unexpected circumstances (e.g. Lopez, 2009; Pedersen and Smithson, 2013; Orton-Johnson, 2017; Jaworska, 2018; MacKenzie, 2018). Mumsnet, from which we sourced the data, is the largest parenting website in the UK and a unique source of PND stories (Jaworska, 2018; Kinloch and Jaworska, 2020). The platform can therefore offer important insights into the mental health condition affecting mothers, which is otherwise not easy to disclose (Woody et al., 2017). We focus in particular on the discourses around the maternal body in distress. Not only is the maternal body subject to societal scrutiny and surveillance; it is also the site through which motherhood is performed (e.g. Kukla, 2005). Our analysis of online accounts of PND explores specifically how the relationship between maternal body and mind is constructed in discussions of postnatal depression.

Mainstream medicine, at least in the West, refers patients with mental health issues to mental health professionals, such as psychologists and psychiatrists, that are entirely separate from practitioners who diagnose and treat physiological conditions (Gold, 1985; Bhugra and Ventriglio, 2017). This separation, which is deeply rooted in the Cartesian body/mind dualism, has contributed to an oversight of the physiological dimension when it comes to mental health issues; and vice versa, physicians are rarely concerned with psychological signs of a disease, which has led, as some argue, to the depersonalisation of physical illness (Gold, 1985). Essentially, the body/mind dualism has 'dissected' human beings into two separate entities mind and body - maintaining the notion that there is little or no connection between the two. While the separation has contributed to advances in modern medicine, it has also limited the understanding of illness (Gold, 1985; Bhugra and Ventriglio, 2017); it has reduced illness to 
either bodily or mental causes, largely ignoring the multidimensional lived-body experience, of which both mind and body are an integral part (Merleau-Ponty, 1962). By exploring livedbody experiences as discussed in posts about PND on Mumsnet, we examine how mothers recontextualise or contest dominant social ideals about the maternal body and maternal mental health and to what extent their stories challenge the dualism model, which still dominates the approach to health and illness in medical practice.

We begin our paper with a brief description of PND - the mental health condition of immediate concern in the data. Subsequently in Section 3, we move on to the maternal body as the site of societal control and performance of motherhood. Section 4 discusses the Mumsnet parenting site from which PND narratives were collected, as well as data collection procedures and issues surrounding the ethics of data collection. Subsequently, a corpus-based approach, which was used to examine the data, is outlined. Section 5 presents the main results and possible interpretations of dominant discourses identified in the data, while section 6 concludes with observations regarding the ways in which bodily experiences are used as an explanatory model for PND and negative maternal affect, and the relationship this has with the understanding of PND.

\section{Postnatal depression}

In psychiatric diagnosis, postnatal depression (PND) is officially defined as a mood disorder with peripartum onset ${ }^{1}$ (DSM V), distinguished from general depression through temporal definition, as it must occur within a specified period pre or post birth. It should be noted however that PND is often used as a catch all term for perinatal mental illness which may include other mood disorders such as anxiety and obsessive-compulsive disorder (Nicolson, 2006). The manifestations of PND include: a persistent feeling of sadness and low mood, lack of enjoyment and loss of interest in the wider world, lack of energy and feeling tired all the time, trouble sleeping at night and feeling sleepy during the day, difficulty bonding with your baby, withdrawing from contact with other people, problems concentrating and making decisions, and frightening thoughts - for example, about hurting your baby (NHS, 2016). Whilst there are several potential predisposing factors including a history of mental health problems, stressful life events or birth trauma, the literature of PND agrees only that the

\footnotetext{
${ }^{1} 4$ to 6 weeks pre and post birth
} 
condition has an uncertain aetiology (Evans, et al. 2012). Biomedical and psychosocial explanations abound but there is no accepted causal paradigm of PND.

PND is thought to affect 10-15\% of women (Woody et al., 2017) and is a leading cause of maternal death in the first year of motherhood. Yet, a study by the National Childbirth Trust found that up to $50 \%$ of women do not seek help for their mental distress. In psychiatric literature, PND is believed to be under-detected and under-treated (Woody et al., 2017), with one explanation for this being the stigmatising nature of a PND diagnosis (Edwards and Timmons, 2005). This stigma may in part result from the negative perception of 'risk' factors for PND, which include history of mental health problems, lack of support network, stressful life events or socio-economic problems (NHS, 2016). It can also arise from societal expectations of what 'good' motherhood entails, including positive emotions around birth and becoming a mother, something that Johnston and Swanson (2003) describe as a happiness imperative to good mothering. Feelings outside this imperative are necessarily repressed and/or suppressed. Hays (1996) relates this suppression of negativity to ideals of intensive mothering, in which mothers' needs are subsumed to the needs of their infant.

Against this background, it is not surprising to see that mothers tend to ascribe PND to personal weakness, struggling with life and not being a good enough mother (Edhborg et al., 2005). As such, PND is experienced as a threat to women's self concept of motherhood (Patel et al., 2013), which disrupts the socially expected 'good' mothering discourse (Button et al., 2017), and for which alternative explanations are sought to maintain the ideal of intensive mothering (Hays, 1996). Social science studies into perceptions of PND and its causes have found participants attributing their experience to a previous history of mental health problems, personality characteristics, physical health problems (Everingham et al., 2006) as well as lifestyle stressors, unmet expectations and loss of self (Patel et al., 2013). Neurobiological explanations for PND based on the notion of 'faulty chemicals in a faulty body' are reported too, especially in online accounts (Jaworska and Kinloch, 2019). These can be 'desirable' because of their potential to depersonalise and consequently destigmatise postnatal mental illness by distancing the self from the 'faulty' body.

Feminist scholars have argued against the medicalisation of the adversities of motherhood, suggesting that PND fills a need for the explanation and diagnosis of bodily effects of motherhood, such as tiredness (Nicolson, 2006). Yet, the body and bodily experiences have to date received little attention in clinical and social science research on PND, which tends to focus on the psychological side of the condition. Before we examine constructions and 
recontextualizations of the maternal body in PND posts on Mumsnet, the next section focuses on the role of the body in the experience of motherhood.

\section{Discourses of the maternal body}

The perinatal body is the subject of social scrutiny, in line with the problematic position which the female reproductive body occupies in society (Martin, 1987). Maternal bodies are viewed as unregulated and unruly, as they "leak, drip, squirt, expand, contract, divide, sag, dilate and expel" (Kukla, 2005: 3). The maternal body is presented as in need of recovery and repair (Upton and Han, 2003; Neiterman and Fox, 2017) or at least in need of monitoring as the well-regulated and well-functioning maternal body is the body of the 'good' mother (Patterson and O’Malley, 2013). In addition to occupying a problematic social space, the maternal body can be problematic for women themselves, representing the site of loss of control (Neiterman and Fox, 2017; Patterson and O’Malley, 2013). Martin (1987) identified separation from a sense of self in the experience of giving birth and the postpartum body. In the interviews she conducted, women frequently referred to the feeling of being fragmented into body parts, which was associated with a lack of control and a sense of autonomy. Martin (1987) argues that this understanding is much imposed by medicine and the kind of medical vocabulary which women are exposed to when they become pregnant and give birth. For example, medicine views the female body as a 'machine', which in order to perform its reproductive 'function' well has to 'labour', 'push' and 'press'. Analysis of discourse on bodily experiences gives insight into the knowledge constructions around these experiences (Paulson and Willig, 2008). Since both subjectivity and embodiment are culturally located (Lupton, 1998), narratives of the body are enacted in relation to these cultural subjectivities and expectations. Studying discourses around maternal bodies can therefore reveal the kind of normative standards that form them and according to which the maternal body should be experienced.

Research into self-reported narratives of maternal bodies has tended to focus on embodied subjectivity in women's stories of their pregnant and postnatal bodies, and how these bodies are experienced in relation to cultural norms of beauty and sexual function (Nicolson et al., 2010; Roth at al., 2012). In general, a changed postnatal body is societally constructed as undesirable and there is a push to 'bounce back' to the pre-pregnancy body shape as quickly as possible post birth (Roth et al., 2012; Patterson and O'Malley, 2013). Specifically, the portrayal of celebrities' post-partum bodies in the media has been shown to set unrealistic 
standards, causing additional pressures during the challenging moments of motherhood, increasing negative feelings such as body image dissatisfaction and having shaming effects (Hopper and Aubrey, 2016). Choi et al. (2005) extend Stoppard's (2000: 92) notion that performing femininity can 'exhaust a woman's body while undermining her morale and sense of well-being' in the performance of motherhood. Thus, the lived experience of the maternal body can considerably influence psychological wellbeing.

Yet, PND research focuses almost exclusively on the psychological side of the condition and how to treat symptoms such as low mood and anxieties, while the physical effects on the body are rarely considered. This may be to do with the predominance of the body/mind dualism, which still prevails in modern medical practice despite the current philosophical thinking which brings the connections and interactions between body and mind to the fore as a part of one system - the lived body (Merleau-Ponty, 1962). For example, research by Kinloch and Jaworska (2020) has shown that discourses of PND in the medical profession focus predominantly on medical and pharmacological treatments of the condition, specifically the use of antidepressants, while information given to patients emphasise emotions and pharmacological solutions, as well as alternative therapies including Cognitive Behavioural Therapy (CBT). The bodily effects of PND are rarely considered, despite the fact that references to the body are quite frequent in PND posts (Kinloch and Jaworska, 2020). Discourses of the maternal body in the context of PND have, however, not been studied in more detail to date. In this paper, we are interested in exploring how broader norms of good mothering and the maternal post-partum body are evoked and recontextualised in online discussions of maternal distress. We specifically ask:

1) What role does the material body play in narrating and sharing the experience of PND online?

2) How do mothers recontextualise or contest dominant societal ideals about the maternal body and maternal mental health in their online accounts of PND?

3) How is the interaction between mind and body enacted in online discourse on PND?

\section{Data and Methods}

4.1 Data and ethics 
This study is based on the examination of a large corpus of posts about PND sourced from Mumsnet. Mumsnet is now the largest parenting website in the UK, with 14 million unique visitors per month and over 128 million page views. Although it is difficult to say precisely who the members of Mumsnet are, a census conducted by Mumsnet in 2009 suggests that they are overwhelmingly middle-class women aged 30 to 40, many of whom have a university degree and are professional working mothers (Mumsnet, 2009). These are important demographic and contextual factors to consider when interpreting data obtained from this online source (cf. Giles, 2016). The website includes a discussion forum, Talk, which is a public forum that can be browsed by members and non-members, but only a registered member can post. We searched the forum for instances of threads containing the terms 'postnatal depression' or 'pnd'. Posts that were in the topical threads were downloaded and turned into a large corpus with 4,778,285 words.

The terms and conditions of Mumsnet stipulate that Talk is a public space and users are made aware that anyone can view their posts. People use pseudonyms to post messages to protect their identity. Some Mumsnet users are well aware of the issues surrounding privacy and anonymity and even change their username frequently, so that they are not easily recognised as a particular Mumsnet persona (MacKenzie, 2017). In fact, the same person may contribute to different topics under different usernames.

There is a great deal of discussion about the ethical use of content from public discussion fora for external research purposes. For example, MacKenzie (2017) recommends paying careful attention to interactional rules and norms of an online community and obtaining consent from participants if research might violate the norms that the community has established. Others suggest that by posting anonymously on a public forum, participants automatically give their consent (Roberts, 2015). Following procedures adopted in previous research using posts from Mumsnet (e.g. Pedersen, 2016), we did not seek consent from the participants because the material used was not directly elicited from them and only obtained after it was spontaneously generated. One approach suggests that researchers collecting online data should post a message about the research on the platform and offer some form of 'data withdrawal' procedure (Koene and Adolphs, 2015). Since we collected a vast number of threads, some of which were posted 15 years ago or so, this proved difficult, especially since we did not have the administrator rights to do so. Also, using the tools and methods of corpus linguistics, we aggregated the data into a large corpus, which was only available to us as researchers. Examples of posts cited in the paper were selected only after the corpus-based analysis had been completed, as instances of the larger discourse patterns that had been identified. Yet, the terms 
and conditions of Mumsnet state that all content published on its site are the sole property of Mumsnet and reproduction of any parts without approval is prohibited. Therefore, we sought consent from Mumsnet to use the Talk data for the purpose of this research and approval was granted. The approval stated that usernames or any other potentially identifying details must be removed to protect posters' anonymity and this procedure was adopted throughout.

\subsection{A corpus-based approach}

The methodology for this study is embedded in the tradition of corpus-based or corpusassisted discourse analysis (Baker, 2006; Partington et al., 2013), carried out using corpus software Wmatrix (Rayson, 2008) and Sketch Engine (Kilgarriff et al., 2004). A corpusassisted discourse analysis aims to uncover "non-obvious meaning, that is, meaning which might not be readily available to naked-eye perusal" (Partington et al., 2013: 11) through analysis of large groupings of texts, corpora.

There has recently been an increasing body of work using corpus assisted discourse studies to better understand the linguistic representations and discourses around particular conditions or illness experiences using online data including depression (Harvey, 2012), cancer (Demmen et al., 2015), infertility (Kinloch, 2018), pain in terminal illness (Jaworska and Ryan, 2018) and diabulimia and anorexia (Hunt and Brookes, 2020). As with many corpus-based or corpusassisted studies exploring discourse or discursive constructions of health or illness, the notion of discourse underpinning our research is based on the poststructuralist notion of discourse as used in Critical Discourse Analysis (Fairclough, 1989; Sunderland, 2004). This, in turn, draws on the Foucauldian definition of discourse as a form of social practices which "systematically form the object of which they speak" (Foucault 1972: 49). From this perspective, discourse is not just a set of words or phrases that describe realities of, for example, health and illness; it is a symbolic means which people use to make sense of and communicate their ideas and beliefs about the world and themselves. Following CDA, we therefore understand discourse as a set of ideas, options and themes that became manifest and can be systematically investigated in texts through paying attention to lexico-grammatical choices (Sunderland 2004). Adding the corpus-linguistic perspective, we are specifically interested in repeated lexical choices, as these can offer "hitherto undescribed insights" (Harvey 2012: 373) that are difficult to access using more qualitative approaches. Further, a corpus-linguistic analysis can point to salient and shared patterns of meanings within a discourse community (Stubbs, 2001), such as that of mothers writing about PND on Mumsnet. 


\section{Keywords and collocates}

One of the useful ways of identifying salient discourses in a given corpus is through the analytical tool of keywords. A keyword is a word which occurs unusually frequent in a given corpus, as compared to another, mostly larger, reference corpus. This unusualness is established by using a statistical test, for example, a log likelihood or log ratio. Keywords are seen as good indicators of the text's aboutness, and pointers to major themes and topics in a given data set. Yet, keywords are essentially isolated lexical items. We know from neo-Firthian and corpus-driven lexicography that the form of a word does not necessarily encompass all the meanings that the word in question has (e.g. Sinclair, 1991). These often arise from the typical combinations of the word with other lexical items. While keywords can help us develop some 'hypotheses' regarding meanings of lexical items, in order to understand what they mean in context, we need to move beyond single words and investigate their 'neighbourhoods'. This can be done by examining collocations and how they are used in context.

Collocation is understood as the co-occurrence of two or more words within a certain span, established on the basis of a statistical test. In a corpus-based discourse analysis, collocations are regarded as useful indicators of lexico-grammatical associations and pointers to salient themes and value judgments associated with a studied item (Mautner, 2007). To explore how collocations 'behave' in their context of usage, we can use the concordance function, which positions a word with a designated span of words to the left and to the right of the item in question. Concordance lines are therefore useful if we want to explore the immediate neighbourhood of a collocation, for example, its evaluators and other lexico-grammatical items in the close vicinity. We used concordance lines to investigate the immediate collocations of selected lexical items. An analysis of instances in a wider textual context is necessary if we want to understand how a collocation is used in discourse. The Sketch Engine tool that we utilised in the present study allows us to access, through concordance lines, longer stretches of texts, thus enabling us to see how a collocation 'behaves' in discourse and in relation to what themes it is used.

\section{Key semantic domains}

Wmatrix is a versatile corpus analytical tool that can annotate words for their semantic meanings. It carries out automated semantic annotation, using the built-in UCREL Semantic Analysis System (USAS) which tags each word of the data with one of 21 major semantic domains (see Figure 1). By comparing the frequency of these domain tags to the tags of the 
larger reference corpus, in this case the written $\mathrm{BNC}$, it is possible to identify key semantic domains. We were aware of the limitations of comparing the BNC to online data (Scott, 2016) ${ }^{2}$. Yet, this is the only reference corpus of British English available as part of Wmatrix. Because we were not interested in register features of online talk but in thematic patterns, we deemed the $\mathrm{BNC}$ to be sufficient as a comparator corpus.

Unlike keywords that are long lists of individual words not semantically or thematically categorised (this is often done manually by the researcher), Wmatrix helps us identify salient and less salient thematic units in a corpus more reliably and efficiently. This is particularly useful for discourse analysts who are often interested in thematic and meaning patterns as opposed to single words. For example, Collins (2015) used Wmatrix to study comments in the British national newspaper The Guardian and was able to identify the key themes in readers' responses to issues pertaining to climate change. Other studies which use semantic domains to explore discourses within a corpus include Demmen et al.'s (2015) work on violence metaphors in cancer texts and Jaworska's (2017) study on metaphors in promotional tourism discourse.

\begin{tabular}{|c|c|c|c|}
\hline $\begin{array}{c}\mathbf{A} \\
\text { general and abstract } \\
\text { terms }\end{array}$ & $\begin{array}{l}\text { B } \\
\text { the body and the } \\
\text { individual }\end{array}$ & $\begin{array}{c}\text { C } \\
\text { arts and crafts }\end{array}$ & $\begin{array}{c}\mathbf{E} \\
\text { emotion }\end{array}$ \\
\hline $\begin{array}{c}\mathbf{F} \\
\text { food and farming }\end{array}$ & $\begin{array}{c}\mathbf{G} \\
\begin{array}{c}\text { government and } \\
\text { public }\end{array}\end{array}$ & $\begin{array}{c}\text { H } \\
\text { architecture, } \\
\text { housing and the } \\
\text { home } \\
\end{array}$ & $\begin{array}{c}\text { I } \\
\text { money and } \\
\text { commerce in } \\
\text { industry } \\
\end{array}$ \\
\hline $\begin{array}{c}\mathbf{K} \\
\text { entertainment, } \\
\text { sports and games } \\
\end{array}$ & $\begin{array}{c}\text { L } \\
\text { life and living things }\end{array}$ & $\begin{array}{c}\mathbf{M} \\
\text { movement, location, } \\
\text { travel and transport } \\
\end{array}$ & $\begin{array}{c}\mathbf{N} \\
\text { numbers and } \\
\text { measurement }\end{array}$ \\
\hline $\begin{array}{c}\text { O } \\
\text { substances, } \\
\text { materials, objects } \\
\text { and equipment }\end{array}$ & $\begin{array}{c}\mathbf{P} \\
\text { education }\end{array}$ & $\begin{array}{c}Q \\
\text { language and } \\
\text { communication }\end{array}$ & $\begin{array}{c}\mathbf{S} \\
\text { social actions, states } \\
\text { and processes }\end{array}$ \\
\hline $\begin{array}{c}\mathbf{T} \\
\text { Time }\end{array}$ & $\begin{array}{c}\text { W } \\
\text { world and } \\
\text { environment }\end{array}$ & $\begin{array}{c}\mathbf{X} \\
\text { psychological } \\
\text { actions, states and } \\
\text { processes }\end{array}$ & $\begin{array}{c}\mathbf{Y} \\
\text { science and } \\
\text { technology }\end{array}$ \\
\hline $\begin{array}{c}\mathbf{Z} \\
\text { names and grammar }\end{array}$ & & & \\
\hline
\end{tabular}

Figure 1: USAS key semantic domains

In this study we employ the affordances of Wmatrix key semantic domains to identify the most frequent topics discussed in the Mumsnet corpus and combine this with Sketch Engine concordance tool to examine contextual patterns of the most frequent words which occurred in

\footnotetext{
2 The BNC was released in 1994; it includes texts collected in the late 1980s and early 1990s and hence it has some limitations for comparisons with texts produced more recently, specifically online texts. The new BNC2014 being compiled by researchers at the University of Lancaster would have been a better comparator, but it is not widely available yet.
} 
the key semantic domains. We identified the body and the individual (domain B) as one of the most key domains and therefore a salient category for collocation and concordance analysis. It is worth noting that each domain contains a number of sub-domains, each relating to a particular semantic category, in the case of domain B these include: B1 (anatomy and physiology), B2 (health and disease), B2+ (healthy), B2- (disease), B3 (medicines and medical treatment), B3-(without medical treatment), B4 (cleaning and personal care), B4+ (clean), B4(dirty), B5 (clothes and personal belongings) and B5- (without clothes). Each word is tagged by USAS to indicate the subdomain and thus keyness is calculated at the level of the sub domain, allowing the possibility of exploring multiple semantic aspects within one overarching domain. This will be discussed in further detail in the following section.

\section{Results and discussion}

Using Wmatrix and its semantic tagger (Rayson, 2008) to elicit the key semantic domains in the Mumsnet corpus, we identified that within the top five sub-domains, three came from Domain B - the Body and the Individual - and included (in order of log likelihood keyness): B1 (anatomy and physiology), B3 (medicines and medical treatment), B2- (disease). The most key of these domains, in order of LL keyness rank, was B1 (anatomy and physiology), an interesting result to emerge from the analysis of data which primarily concerns a psychological condition and therefore a salient point for further investigation (see Table 1).

\begin{tabular}{|l|l|r|}
\hline \multicolumn{1}{|c|}{ KEY SEMANTIC DOMAIN } & USAS TAG & Log Likelihood \\
\hline Time: New and young & T3-- & 3516.72 \\
Anatomy and physiology & B1 & 2232.76 \\
Medicines and medical treatment & B3 & 1890.09 \\
Sad & E4.1- & 1472.18 \\
Health and disease & B2- & 1327.57 \\
Degree: Boosters & $\mathbf{A 1 3 . 3}$ & 1042.62 \\
Measurement: Weight & $\mathbf{N 3 . 5}$ & 1016.40 \\
Helping & $\mathbf{S 8 +}$ & 928.13 \\
Expected & $\mathbf{X 2 . 6 +}$ & 708.52 \\
Food & F1 & 655.00 \\
\hline
\end{tabular}

Table 1: Keywords semantic domains in the Mumsnet corpus using Wmatrix software 
The high keyness of the subdomain 'anatomy and physiology' suggests that the body and terms pertaining to the body are potentially significant in the lived experience of this mental health condition, providing a potential challenge to the dominant body/mind dualistic model that prevails in medical practice (Gold, 1985; Bhugra and Ventriglio, 2017). It is possible in Wmatrix to explore the terms tagged in a particular domain, thus enabling us to identify the most frequent lexical items which comprise this domain. When domain B1 was explored in more detail this revealed the top 10 most frequent terms in this domain, as shown in Table 2.

\begin{tabular}{|l|r|}
\hline Lexical item & Frequency in category B1 \\
\hline sleep & 278 \\
\hline birth & 127 \\
\hline pregnancy & 109 \\
\hline breast & 102 \\
\hline sleeping & 89 \\
\hline born & 87 \\
\hline pregnant & 86 \\
\hline body & 64 \\
\hline tired & 62 \\
\hline head & 60 \\
\hline
\end{tabular}

Table 2: Keywords in the Mumsnet corpus relating to the body or to bodily experiences

Taking the most frequent words in the category B1 (anatomy and physiology), we decided for the purpose of this analysis to explore the discourses around two selected keywords, body and sleep, through the examination of these terms in context. These terms were of particular interest because they showed high salience in a corpus of texts on the perinatal experience of women.

The word BODY occurs 972 times in the Mumsnet corpus. A concordance analysis of this term elicited the most frequent patterns around BODY as my body, your body, and body and; it is these two-word phrases which provided the focus for our analysis. In what follows, we present and discuss the recurrent and therefore salient discourses around the maternal body identified through these frequent patterns of use and the analysis of their contexts. In order to identify the salient discourses, all 927 concordance lines with the item BODY were first 
grouped into 'batches' containing the most frequent collocation pairs my body, your body and body and. The three sets were then annotated with the themes that were talked about in the post by expanding the concordance lines to the longer stretch of text. The two researchers performed the analysis first separately; results were then compared, with 'diverging' cases resolved upon mutual agreement. The dominant themes identified are discussed below.

\section{Demands on the body}

The phrase 'your body' is used in discursive responses both as a referent to a previous poster's body and to the collective maternal body. In both cases it is primarily used to provide reassurance and explanation to a poster who is in distress. Examples 1 and 2 show how emotional responses to physical trauma are normalised in discourse, with physical disruption presented as an explanation for psychological disruption. In these examples the body is described in terms of violence enacted upon it, as indicated though the use of terms such as 'battered' and 'trauma':

1. Your body is battered, you've had about 3 hours sleep in one go (if you're lucky) for at least a fortnight - go easy on yourself.

2. Your body has been through a trauma, you are sleep deprived and exhausted, your hormones are seriously disrupted and your brain chemicals have gone out of balance. This is NORMAL and PND is very common.

The physicality of birth and mothering is presented as a trial to be endured, the body is acted upon by circumstances and this action is used as an explanation for distress. The agency for this is removed from individuals experiencing it and now it is the body which turns into the role of the experiencing patient. Thus, in the context of PND experience the body can potentially act as a destigmatising factor, reducing the blame on the individual; it is the physical body which takes the 'hit', while the 'self' is spared. The physical demands placed on the maternal body can therefore be used as mitigation for negative emotions and experiences.

\section{Comparison to physical illness}

Another recurring discursive practice around the body and PND, is to encourage posters to view their experience in equivalence with physical illness or injury, as seen in Examples 3-5. 
In these examples, the body/mind dualism is rejected and the mind framed as a part of the body, validating helpseeking and attempting to destigmatise mental illness:

3. If you had broken your leg you wouldn't be a failure; if you had flu you wouldn't be a failure. This is just a different part of your body that is ill, that's all.

4. It's so important to tell people how you feel - it's not a personality failing, it's just your body making you feel like this.

5. If you were diagnosed with a potentially fatal physical illness, like diabetes or cancer, would you refuse to take medication? Your mind is part of your body, after all.

\section{Neurochemical explanations for PND}

A complementary discourse to the promotion of parity between mental and physical illness, is the recurrent reference to neurochemical explanations for PND, framing it in terms of neurological (Example 6) or hormonal (Example 7) activity which is, crucially, outside of the control of the individual:

6. You have coped with too much for too long and your body can't take the strain so something has to give - the limbic system, which controls mood.

7. Please, please don't underestimate the amount of hormones swilling about in your body . Even if it's not bad enough to call it true PND, they can make you feel mildly weird and unable to cope, and depress your libido.

Neurochemical explanations are also used in support of helpseeking and encouragement to engage in biomedical treatment for postnatal mental distress, as illustrated in Example 8. The negative feelings experienced by the mother are attributed to the 'imbalance' of neurochemicals (see Example 9), which is potentially helpful in terms of reducing stigmas because it is a) treatable and b) not something within the agency of an individual. However, this discourse can also problematically contribute to negative representations of the 'unbalanced' female mind:

8. Like you, I was very anxious about taking them, and really didn't want to need to take antidepressants but as I mentioned upthread an imbalance in your body is not a weakness in your mind, so don't feel as though you are 'failing' or 'giving in'. 
9. I think it was the 'chemical' alterations in my body and brain that triggered those 'feelings'.

While disassociating the self from the body can be helpful in terms of reducing stigma, it is worth noting that it also removes agency from the individual. As loss of control is one of the suggested explanations for perinatal depression, discourses which minimise agency could also be problematic: as seen in the next section, a lack of agency is one of the explanations offered for perinatal distress. Therefore, any decrease in agency could potentially reinforce this distress, rather than mitigate it.

\section{Bodily agency and control}

While, as discussed above, a lack of agency over mental and physical changes can be used to destigmatise negative affect, this can also be problematic and part of a discourse of loss of self. The loss of agency and specifically, of bodily agency, is marked in these texts as an inevitable consequence of mothering, as illustrated in Example 10:

10. Oh and yes, your brain kind of goes for awhile, and your body.

The control of ones' own body is shown as the core of one's sense of control over self, thus when bodily agency is absent, mothers in the Mumsnet corpus equate this with a loss of selfhood. As seen in Examples 11-13, the loss of self is strongly linked with the loss of bodily ownership. In all three excerpts, the writers describe the body as a space which was previously under their ownership, which was 'lost' to the pregnancy. The need and the wish to return to this agentic state is also a recurrent theme in the data:

11. With the first pregnancy I felt that everything had been taken from me, my body and my mind.

12. I wanted my life and my body and my sleep and my sense of separate self back.

13. I got sick of being sat on, lay on, pulled on whined at etc. My body was never my own and a trip to the loo on my own when dh [dear husband] came in from work was a real treat.

In the more extreme examples of lost bodily agency, mental distress is located and manifested in the physical body. For example, the excerpts below exemplify a lack of control with either 
body (as in Example 15) or mind acting upon the self (as in Example 14). In these excerpts, loss of agency in PND/motherhood coexists with high levels of mental distress:

14. Sometimes I want to escape from myself so badly I can hardly breathe. My own body is like a prison and I desperately need to break free.

15. My nights are so filled with anxiety I can't bear it. My body is so so tired, yet something in my mind fights sleep and just won't let go.

In contrast, the return to bodily ownership is equated with a regained sense of self. In responses that reassure those expressing distress, improvements in the maternal self are marked by a return to bodily agency, to reduced demands on the maternal body:

16. Your baby grows up, you get your body back, you get some sleep etc

17. I don't mind telling you - once I started bottle feeding I was out for the night now and then and loved having my body back and that feeling of pure freedom.

Interestingly, this is expressed not just as a reassurance, as in Example 16, but in the form of a confessional discourse, as in Example 17, again indicating that the desire to return to the nonmaternal body may be construed as not exactly compatible with the ideal of good mothering.

While the previous section addressed the term 'body' in exploring the embodied experience of PND, in the following analyses we look at a specific physical function, 'sleep' (as a noun). In particular we look at the lack thereof, as the most frequent patterns of 'sleep' found in the concordance analysis cluster around this concept and include; 'deprivation', 'deprived', and 'loss'. 'Sleep' as a verb is more frequent yet it refers to infant sleep patterns not to mothers and for this reason has not been included in the analysis.

\section{Lack of sleep as causal explanation}

A number of posters in the Mumsnet corpus (Examples 18-20) make an explicit link between their experience of sleep deprivation and subsequent mental illness, particularly highlighting the chronic nature of lack of sleep. In these cases, the posters' retrospective analysis and sensemaking of their mental distress is centred around sleep deprivation, a circumstance almost inevitable to new parents. It is expressed not as conjecture but with certainty, allowing no space to contest the embodied experience: 
18. My PND was certainly caused/exacerbated by extreme sleep deprivation.

19. Anyway I firmly believe that my PND was triggered/prolonged by months of sleep deprivation.

20. Looking back I can see now how the sleep deprivation of having a new baby set me off on a spiral of ever worsening anxiety.

This kind of discourse allows mental illness to be framed in terms of justifiable bodily experience and again this may function as a way to destigmatise and normalise it as a response to the embodied maternal experience.

\section{Sleep deprivation or PND?}

Sleep deprivation is used as a common explanation for mental distress in mothers. Yet, it is also used to argue against a formal diagnosis of PND or other diagnosed mental health conditions. This is manifest in hedging constructions (e.g.: 'could', 'probably', 'I reckon'), indicating a distancing strategy or disbelief as in Examples 21-22. Sometimes, PND is explicitly refuted in the face of sleep deprivation, as in Example 23. While it is helpful to consider the causal link between sleep deprivation and mental distress, the implication that sleep deprivation is a proxy for PND might be problematic. It also potentially points to a collective will to avoid diagnosis if possible:

21. It could be PND but it could also be sleep deprivations making you think/feel like this?

22. I probably have had PND too, though to be frank, I was suffering acute sleep deprivation for months - that'll fuck with your emotions like nothing else will!

23. I don't think you necessarily have PND, I reckon you are stressed and sleep deprived beyond endurance.

The desire not to label the experience of perinatal mental distress as PND, while valid for individuals, can be problematic, as encouragement to reject medical diagnosis may increase stigma and discourage helpseeking. The risk of 'armchair' diagnosis in online interaction is one of the potential negative factors of online helpseeking for medical conditions, in particular mental health.

\section{Multifaceted explanations for PND}


In contrast with the discourse of sleep deprivation as an alternative to diagnosis of PND, multiple posters draw on the discourse of multifaceted explanations for PND. In Examples 2426 , the posters draw on other well known explanatory tropes for PND, including hormones and life stress combined with sleep deprivation, in seeking to provide reassurance about the experience of PND:

24. It is quite possible that you have PND, and if you seek help things can become a lot more manageable with support. Additionally, remember you have only recently gone through the biggest lifechange ever and this added to the really awful experience that is sleep deprivation can really be totally exhausting physically and emotionally.

25. Sleep deprivation and stress are extremely harmful, in your case they interacted with hormones and the experience of birth.

26. The GP was very sympathetic...and said that the next few weeks are just about survival, and that it is my hormones and sleep deprivation that make me feel so desperate, not that I am turning into a crazy woman! She has given me prozac.

Normalising distress as a combination of hormones, sleep deprivation and new motherhood may be helpful for women experiencing PND, as it can potentially reduce blame and stigma. However, like previous embodied explanations, it also removes agency. Interestingly, neurochemical disruption and sleep loss as causes of PND do not preclude medical treatment (as seen in Example 26).

\section{Sleep deprivation and 'bad' mothering}

As well as being described as a causal factor for mood disorders, sleep deprivation is used to mitigate negative feelings about motherhood, and thus allows the expression of these feelings. Implicit in this mitigation is the recognition that disclosure of negative emotions and bodily reactions is generally considered unacceptable because these kinds of experiences are simply seen as 'unnatural' reactions to motherhood:

27. God how much did I hate Motherhood, it nearly killed mine and DHs [dear husband] relationship, I was sleep deprived, depressed and hallucinating.

28. The sleep deprivation and the crying nearly killed me. I remember thinking "something isn't right, it can't be this hard for everyone". 
29. Take a step back, anyone cried at all day and sleep deprived would feel bad - if that's PND - I call it the reaction of a sane person. You are just brave enough to express normal reactions - which many aren't because they are thought to be "unnatural".

Regardless of whether mental distress is recognised as PND, or as one poster states, 'commonor-garden sleep deprivation', the high impact it has on the embodied experience of new motherhood is almost universally acknowledged on the Mumsnet posts. Lack of sleep is presented as operating within a vicious cycle; trouble sleeping is one of the potential manifestations of (postnatal) depression, and lack of sleep can cause mental distress. Even in examples in which the poster acknowledges a mood disorder diagnosis, still the normalising of a high level of physical discomfort i.e. sleep deprivation, in the early stages of motherhood is highlighted. This may reinforce the idea that suffering is a normal act of motherhood.

\section{Discussion and Conclusions}

The above analysis of online stories of PND has demonstrated the prominence given to the body and embodied experience when negotiating the tensions between psychological disorder and the physiological experience of mothering. Through what can be termed 'bodily confessions', mothers attempt to manage their experience by validating, destigmatising, mitigating and at times dismissing mental illness. Yet, the body is not solely seen as a physical object. Rather, it is a multidimensional site of a lived-body experience, in which physical and psychological elements constantly interact. While seeing the maternal body as a physical object can help women to dissociate the self from their 'diverging' experiences and potentially reduce the stigma associated with PND, the body is also a site of emotional struggles associated with the loss of control and the loss of self. As our analysis has shown, reclaiming ownership of the body can also mean reclaiming a sense of control and agency, which in our data has been associated with the experience of recovery.

In the explanations given for their experiences of PND, mothers point to and acknowledge the interactions of multiple factors: the relationship between feeding, childcare and loss of bodily autonomy (and thus sense of self), and the interaction between sleep deprivation, bodily discomfort and poor mental health, are both found in the discussions. These explanations reinforce the complex aetiology of perinatal mental illness, which is rarely found in the biomedical literature on the topic. In our study, we also found that online disclosures of maternal distress are met with pseudo-diagnostic responses, usually in the form of experiential 
knowledge, normalising and managing the bodily experience to contain it within societally 'acceptable' boundaries of good mothering. However, some explanatory models can be used to minimise disclosures of PND, as we found with repeated instances of 'it's probably not PND - just extreme tiredness/bodily disruption'. In such explanations, 'normal' bodily experiences of motherhood such as sleep and hormonal changes are used as explanations for mental distress which could be problematic as they normalise embodied suffering in motherhood. The experience of 'normal' bodily discomfort in the postpartum period may be exacerbated by expectations of intensive mothering (in which one's body is not one's own), maternal sacrifice (sleep deprivation) and 'recovery' from childbirth.

Armstrong et al. (1998) reported that it is likely significant numbers of mothers being diagnosed as having postnatal depression are suffering the effects of chronic sleep deprivation. This finding is borne out by the strong bidirectional relationship which posters use to describe sleep and mental distress in the postpartum period, in which they are either drawing on biomedical discourses of sleep deprivation equals PND or that the lived experience supports further investigation in the relationship between sleep and maternal mental health.

If high levels of mental and physical discomfort are normalised in lay discourses around mental health, then those who find such discomfort unbearable may experience additional stigma. This leads to the question - is embodied discomfort just another expectation of mothers? And is it, as Paradice (1995) states, that "PND is an understandable response to the demands of motherhood"? Across the contextual examples of 'your body', 'my body' and 'sleep loss/deprivation' in the Mumsnet Corpus, the embodied experience is privileged but physiological discomfort is often positioned as a side effect of motherhood. In more general terms, the heavy focus on bodily explanations for mental health in the Mumsnet corpus suggests that the traditional body/mind dualism, on which modern medicine and its approach to health and illness are based, does not always apply to the lived experience of ill mental health. As our analysis has shown, mind and body constantly interact and are discursively enacted by the 'postpartum self', transgressing the boundaries that the dualistic model sets.

\section{References}

Baker, P., 2006. Using corpora in discourse analysis. Continuum, London.

Butler, J., 1990. Gender trouble: feminism and the subversion of identity. Routledge, London. Button, S., Thornton, A., Lee, S., Shakespeare, J., Ayers S., 2017. Seeking help for perinatal psychological distress: a meta-synthesis of women's experiences. British Journal of General Practice. 67 (663), 692-699. 
Choi, P., Henshaw, C., Baker, S., Tree, J., 2007. Supermum, superwife, supereverything: performing femininity in the transition to motherhood. Journal of Reproductive and Infant Psychology. 23 (2), 167-180.

Collins, L., 2015. How can semantic annotation help us to analyse the discourse of climate change in online user comments? Linguistik online. 70 (1), doi: 10.13092/lo.70.1743.

Demmen, J. E., Semino, E., Demjen, Z., Koller, V., Hardie, A., Rayson, P., Payne, S., 2015. A computer-assisted study of the use of violence metaphors for cancer and end of life by patients, family carers and health professionals. International Journal of Corpus Linguistics. 20 (2), 205-231.

Edhborg, M., Friberg, M., Lundh, W., Widström, A., 2005. Struggling with life: narratives from women with signs of postpartum depression. Scandinavian Journal of Public Health. 33, 261-267.

Edwards, E., Timmons, A., 2005. A qualitative study of stigma among women suffering postnatal illness. Journal of Mental Health.14 (5), 471-481.

Evans, M., Donelle, L., Hume-Loveland, L., 2012. Social support and online postpartum depression discussion groups: A content analysis. Patient Educatation Counsel. 87 (3), 405-410.

Everingham, C. R., Heading, G., Connor, L., 2006. Couples' experiences of postnatal depression: a framing analysis of cultural identity, gender and communication. Social Science and Medicine. 62, 1745-1756.

Fairclough, N., 1989. Language and power. Longman, Harlow.

Foucault, M., 1972. The archeology of knowledge and the discourse on language. Pantheon, New York.

Giles, D., 2016. Observing real-world groups in the virtual field: The analysis of online discussion. British Journal of Social Psychology. 55 (3), 484-498.

Gold, J., 1985. Cartesian dualism and the current crisis in medicine - a plea for a philosophical approach: discussion paper. Journal of the Royal Society of Medicine. 78, 663-666.

Hall, P. C., 1998. Mothering mythology in the late twentieth century: Science, gender lore and celebratory narrative. Canadian Woman Studies. 18, 59-63.

Harvey, K., 2012. Disclosures of depression: using corpus linguistics methods to interrogate young people's online health concerns. International Journal of Corpus Linguistics. 17 (3), 349-379.

Hays, S., 1996. The cultural contradictions of motherhood. Yale University Press, New Haven.

Hopper K. M., Aubrey J. S., 2016. Bodies after babies: The impact of depictions of recently post-partum celebrities on non-pregnant women's body image. Sex Roles. 74, 24-34.

Hunt, D., Brookes, G., 2020. Corpus, discourse and mental health. Bloomsbury, London.

Jang. J., Dworkin, J., 2014. Does social network site use matter for mothers? Implications for bonding and bridging capital. Computers in Human Behavior. 35, 489-495.

Jaworska, S., 2017. Metaphors we travel by: a corpus-assisted study of metaphors in promotional tourism discourse. Metaphor and Symbol. 32 (3), 161-177.

Jaworska, S., 2018. 'Bad' mums and the 'untellable': narrative practices and agency in online stories about postnatal depression on Mumsnet. Discourse, Context and Media. 25, 2533.

Jaworska, S., Kinloch, K., 2018. Using multiple data sets. In Taylor, C., Marchi, A., (Eds.), Corpus approaches to discourse: A critical review. Routledge, London, pp. 110-129.

Jaworska, S., Ryan, K., 2018. Gender and the language of pain in chronic and terminal illness: a corpus-based discourse analysis of patients' narratives. Social Science \& Medicine. 215, 107-114.

Johnston, D., Swanson, D., 2003. Invisible mothers: A content analysis of motherhood ideologies and myths in magazines. Sex Roles. 49 (1-2), 21-33. 
Kantrowitz-Gordon, I., 2013. Internet confessions of postpartum depression. Issues in Mental Health Nursing 34. (12), 874-882.

Kilgarriff, A., Rychlý, P., Smrz, P., Tugwell, D., 2004. The Sketch Engine. Proc EURALEX 200. Lorient, France, pp. 105-116.

Kinloch, K., 2018. A corpus-assisted study of the discourses of infertility in UK blogs, news articles and clinic websites. PhD thesis. Lancaster University, Lancaster.

Kinloch, K., Jaworska, S., 2020. Using a comparative corpus-assisted approach to study health and illness discourses across domains: The case of postnatal depression (PND) in lay, medical and media texts. In Demjen, S. (Ed.), Applying Linguistics in Illness and Healthcare Contexts. Bloomsbury, London, pp. 73-98.

Koene, A., Adolphs, S., 2015. Ethics considerations for corpus linguistic studies using Internet resources. HORIZON: University of Nottingham. Available at. wp.horizon.ac.uk/wpcontent/uploads/2015/04/CL2015-CorpusLinguisticsEthics_KoeneAdolphs.pdf. Accessed on 25 June 2020.

Kukla, R., 2005. Mass hysteria: Medicine, culture and mothers' bodies. Rowman and Littlefield, Lanham, MD.

Bhugra, D., Ventriglio, A., 2017. Mind and body: physical health needs of individuals with mental illness in the 21st century. World Psychiatry. 16 (1), 47-48.

Locher, M., 2006. Advice online: Advice-giving in an American Internet health column. Benjamins, Amsterdam.

Lopez, L. K., 2009. The radical act of "mummy blogging": Redefining motherhood through the blogosphere. New Media \& Society. 11, 729-747.

Lupton, D., 1998. The emotional self: A sociocultural exploration. Sage, London.

MacKenzie, J., 2017. Identifying informational norms in Mumsnet Talk: A reflexive-linguistic approach to Internet research ethics. Applied Linguistics Review. 8 (2-3), 293-314.

MacKenzie, J., 2018. Language, gender and parenthood online: Negotiating motherhood in Mumsnet Talk. Routledge, London.

Martin, E., 1987. The woman in the body. Beacon Press, Boston, MA.

Merleau-Ponty, M., 1962. The phenomenology of perception. London: RKP.

Mumsnet, 2009. Mumsnet census 2009. < https://www.mumsnet.com/archive/census-2009> (last accessed 06 October 2020).

Neiterman, E., Fox, B., 2017. Controlling the unruly maternal body: Losing and gaining control over the body during pregnancy and the postpartum period. Social Science \& Medicine, $174,142-148$

NHS (2016), 'Postnatal Depression', available online: http://www.nhs.uk/Conditions/Postnataldepression/Pages/Introduction.aspx (accessed 06 October 2017).

Nicolson, P., 2006. Post-natal depression: Psychology, science and the transition to motherhood. Routledge, London.

Nicolson, P., Fox, R., Heffernan, K., 2010. Constructions of pregnant and postnatal embodiment across three generations: Mothers', daughters' and others' experiences of the transition to motherhood. Journal of Health Psychology. 15 (4), 575-585.

Orton-Johnson, K., 2017. Mummy blogs and representations of motherhood: "Bad mummies" and their readers. Social Media + Society. 3 (2), 1-10.

Paradice, K. 1995. Postnatal depression: a normal response to motherhood? British Journal of Midwifery. 3, 632-635.

Partington, A., Duguid, A., Taylor, C., 2013. Patterns and meanings in discourse. Theory and practice in corpus-assisted discourse studies (CADS). Benjamins, Amsterdam.

Patel, S., Wittkowski,A., Fox, J. R. E., Wieck, A., 2013. An exploration of illness beliefs in mothers with postnatal depression. Midwifery. 29 (6), 682-689. 
Patterson, M., O’Malley, L., 2013. Bouncing back: Reclaiming the body from pregnancy. In O’Donohoe, S., Hogg, M., MacLaran, P., Martens, L., Stevens, L., (Eds.), Motherhoods, markets and consumption, Routledge, London, pp. 131-144.

Paulson, S., Willig, C., 2008. Older women and everyday talk about the ageing body. Journal of Health Psychology. 13 (1), 106-120.

Pedersen, S., 2016. The good, the bad and the 'good enough' mother on the UK parenting forum Mumsnet. Women's Studies International Forum. 59, 32-38.

Pedersen, S., Smithson, J., 2013. Mothers with attitude - How the Mumsnet parenting forum offers space for new forms of femininity to emerge online. Women's Studies International Forum. 38, 97-106.

Rayson, P., 2008. From key words to key semantic domains. International Journal of Corpus Linguistics. 13 (4), 519-549.

Roberts, L.D., 2015. Ethical issues in conducting qualitative research in online communities. Qualitative Research in Psychology. 12 (3), 314-325.

Roth H., Homer C., Fenwick J., 2012. Bouncing back: How Australian's leading women's magazines portray the postpartum body. Women and Birth, 25, 128-134.

Scott, M., 2016. In search of a bad reference corpus. In Dawn, A. (Ed.), What's in a word-list? Routledge, London, pp. 99-112.

Sinclair, J., 1991. Corpus, concordance, collocation. Oxford University Press, Oxford.

Stoppard, J. M., 2000. Understanding depression: feminist social constructionist approaches. Routledge, London.

Stubbs, M., 2001. Words and phrases: Corpus studies in lexical semantics. Blackwell, Oxford.

Sunderland, J., 2004. Gendered discourses. Palgrave Macmillan, Basingstoke.

Upton R. L., Han S. S., 2003. Maternity and its discontents: 'Getting the body back' after pregnancy. Journal of Contemporary Ethnography. 32, 670-692.

Woodward, K., 2003. Representations of motherhood. In Earle, S., Letherby, G., (Eds.), Gender, identity and reproduction, Palgrave Macmillan, New York, NY, pp. 18-32.

Woody, C. A., Ferrari, A. J., Siskind, D. J., 2017. A systematic review and meta-regression of the prevalence and incidence of perinatal depression. Journal of Affective Disorders. 219, 86-92. 